\title{
Representações sociais de amor romântico nas músicas mais tocadas nas rádios brasileiras em 2015
}

\author{
Representaciones sociales del amor romántico en las canciones más \\ escuchadas en la radio brasileña en 2015
}

\section{Social representations of romantic love in Brazil's most played radio songs in 2015}

\section{Marco Antonio de Deus Pontual ${ }^{\mathrm{a}} \mathfrak{C}^{\circ}$ e Mariana Bonomo $^{\mathrm{a}}{ }^{(0 ;}$;}

\footnotetext{
${ }^{a}$ Mestre em Psicologia pela Universidade Federal do Espírito Santo, Vitória/ES, Brasil. Endereço instiucional: Programa de Pós-Graduação em Psicologia. Universidade Federal do Espírito Santo - UFES. Av. Fernando Ferrari, 514, Edifício Lídio de Souza, Goiabeiras, CEP 29075-910, Vitória - ES, Brasil. E-mail: marcopontual@gmail.com

${ }^{\mathrm{b}}$ Doutora em Psicologia pela UFES. Professora do Departamento de Psicologia Social e do Desenvolvimento e do Programa de Pós-Graduação em Psicologia da Universidade Federal do Espírito Santo, Vitória/ES, Brasil. E-mail: marianadalbo@gmail.com
}

Resumo: O objetivo deste estudo foi analisar as representações sociais de amor romântico contidas nas letras das músicas em português mais executadas nas rádios brasileiras no ano de 2015. Foram analisadas 95 canções, identificadas a partir do software de monitoramento de rádio AudioMonitor. Para tratamento dos dados, as letras das músicas foram submetidas à análise da classificação hierárquica descendente, procedida por meio do software Alceste, que indicou a existência de quatro classes. Os resultados demonstram que as representações sociais de amor romântico apresentadas nas canções analisadas seguem um roteiro estável, orientado pelas fases do relacionamento romântico (corte, lua de mel, curso descendente, e fim) e se apresentam, frequentemente, como justificadoras da heteronormatividade e de comportamentos sociais.

Palavras chave: amor romântico, rádio, representações sociais, música

Resumen:El objetivo de este estudio fue analizar las representaciones sociales del amor romántico contenidas en las letras de las canciones portuguesas más interpretadas en las radios brasileñas en 2015. Analizamos 95 canciones, identificadas por el software de monitoreo de audio AudioMonitor. Para el tratamiento de los datos, las letras se sometieron al análisis de clasificación jerárquica descendente, realizado por el software Alceste, que indicó la existencia de cuatro clases. Los resultados demuestran que las representaciones sociales del amor romántico presentadas en las canciones analizadas siguen un guión estable, guiado por las fases de la relación romántica (corte, luna de miel, curso descendente y final) y a menudo se presentan como justificando la heteronormatividad y comportamientos sociales.

Como citar o artigo: PONTUAL, M. A. de D.; BONOMO, M. Representações sociais de amor romântico nas músicas mais tocadas nas rádios brasileiras em 2015. Revista de Ciências Humanas, Florianópolis, v. 53, 2019 DOI: $10.5007 / 2178-4582.2019 . e 48658$ você pode compartilhar, adaptar, para qualquer fim, desde que atribua a autoria da obra, forneça um link para a licença, e indicar se foram feitas alterações. 
Palabras clave: amor romántico, radio, representaciones sociales, música.

\begin{abstract}
This article aims at analyzing the social representations of romantic love found in the lyrics of the most played songs in Portuguese in Brazilian radio stations in 2015. We analyzed 95 songs, which were identified through a radio monitoring software, AudioMonitor. The data analysis was conducted using the descending hierarchical classification analysis tool of the software Alceste, which identified the existence of four classes. The results show that the social representations of romantic love presented in the lyrics of the analyzed songs follow a stable script of a romantic relationship (court, honeymoon, descending course and end) and often present themselves as justifiers of heteronormativity and social behaviors.
\end{abstract}

Keywords: romantic love, radio, social representations, music

\title{
1 INTRODUÇÃO
}

Em 1922, em virtude da celebração do centenário da independência do Brasil, foi organizada, na cidade do Rio de Janeiro, a Exposição do Centenário da Independência, onde diversos países apresentavam, em stands distintos, uma novidade. O stand norte-americano, através da empresa Westinghouse Electric, demonstrou o funcionamento de uma emissora de rádio, tendo desembarcado no Rio de Janeiro, algum tempo antes, com uma estação completa, e instalado um transmissor no alto do Corcovado. No dia 7 de setembro ocorria, assim, a partir do pavilhão norte-americano da feira, a primeira transmissão radiofônica no Brasil. A mensagem difundida foi o discurso do então Presidente, Epitácio da Silva Pessoa, que pôde ser apreciado por aqueles que estivessem em posse de um dos 80 receptores seletivamente distribuídos pela região. Além do discurso do Presidente, a programação contou, ainda, com música clássica e a ópera O Guarani, de Carlos Gomes (VIRGÍlLIO, 2012).

Da criação da primeira estação de rádio brasileira até os dias atuais, muitas foram as mudanças tecnológicas e sociais sucedidas, as quais serão exploradas no decorrer deste estudo. Por ora, podemos reafirmar a persistente relevância desse meio de comunicação em massa, como demonstram pesquisas realizadas pelo Kantar Media do Instituto Brasileiro de Opinião Pública e Estatística (IBOPE). De acordo com o estudo comparativo Dimension - 2018, por exemplo, realizado com os cinco maiores mercados de mídias no mundo (Brasil, China, França, Reino Unido e EUA) e desenvolvido por meio de entrevistas com os chamados "consumidores conectados" (pessoas que usam entre dois e três diferentes recursos para acessar a internet), o número de ouvintes brasileiros de rádio chega a $91,9 \%$, com $81,5 \%$ utilizando a mídia de rádio on-line (IBOPE, 2018a). Já o relatório Book de Rádio - 2018, baseado em dados de 13 regiões metropolitanas brasileiras, informa que $86 \%$ dos brasileiros declararam ouvir rádio com frequência (de cada 05 pessoas, 03 ouvem rádio diariamente), e 62\% destacam que a música é importante para sua vida (IBOPE, 2018b). Tal dado sugere provável relação entre o que é veiculado nas rádios e o que é consumido, em termos musicais, pelo povo brasileiro, ainda que parcialmente.

\subsection{MÚSICA E AMOR ROMÂNTICO}

A música tem se mostrado um campo profícuo para o estudo de fenômenos psicossociais e, não por acaso, as últimas décadas viram crescer o número de publicações internacionais no campo das Ciências Humanas dedicadas à análise da relação entre a música e a sociedade (BARRAUD, 1975; BENNETT, 2000; NATTIEZ, 1990; RAYNOR, 1986). Não só isso, aspectos específicos do comportamento social expressos nas músicas, tais como o envelhecimento (ADAY; AUSTIN, 2000), o uso e o abuso de substâncias psicoativas (MARKERT, 2001), os aspectos políticos e ideológicos da música (VAN SICKEL, 2005), os estereótipos (SANTOS, 2006), a vida conjugal (COUTINHO, et al., 2015) e o bem-estar psicológico (MIRANDA; GODELI, 2003), têm sido discutidos em publicações acadêmicas nacionais e internacionais da Psicologia Social. O fenômeno psicossocial sobre o qual o presente estudo se ocupa é, por sua vez, o amor romântico (MARTINS-SILVA, TRINDADE, JUNIOR, 2013). 
Nos Estados Unidos, os primeiros estudos utilizando letra de música como fonte de dados datam da década de 1940 (FRITH, 2007). As primeiras publicações sobre o tema, como a pesquisa de Peatman (1944), já ressaltavam a preponderância da temática romântica nas letras das músicas populares, o que Frith (2007, p. 81) classifica como "a ideologia sentimental da sociedade capitalista". Em seu trabalho seminal, Peatman (1944) examinou as 90 canções mais populares dos anos 1941 e 1942 e observou que apenas $8 \%$ delas não se referiam a alguma dimensão do amor romântico. Não só o tema era recorrente, como seus desdobramentos gerais também se tornaram previsíveis. De acordo com o autor (PEATMAN, 1944), as canções tratavam invariavelmente de uma das três dimensões: a do apaixonado feliz, a do apaixonado frustrado ou a de aspectos relacionados a interações sexuais. Em pesquisas posteriores, como nas de Horton (1957), Dukes et al. (2003) e Scheff (2011), também foi observado que o amor romântico era o tema central das letras das canções estadunidenses mais populares.

No Brasil, um estudo que utilizou as letras das canções mais tocadas nas rádios como fonte de dados (PONTUAL; SILVA; BONOMO, 2016) chegou à conclusão similar: apenas 08 das 100 canções mais executadas no território brasileiro, em 2014, não se referiam a alguma dimensão do amor romântico. Não só isso, o próprio conteúdo das canções brasileiras contemporâneas se assemelhava àquele priorizado nas produções musicais estadunidenses (HORTON, 1957): prólogo, corte, lua-de-mel, curso descendente e solidão.

O amor, na condição de temática privilegiada das canções populares, recebe também atenção permanente de pesquisas na Psicologia Social. Em um experimento, conduzido por Jacob et al. (2009), foi constatado que clientes do sexo masculino expostos a músicas românticas em floriculturas gastavam mais dinheiro do que aqueles não expostos a músicas de fundo, ou a músicas não românticas. No mesmo sentido, em um estudo experimental subsequente, foi observado que mulheres jovens expostas a músicas românticas tinham maior propensão a responder positivamente ao cortejo masculino do que aquelas expostas a canções neutras, por exemplo (GUÉGUEN; JACOB; LAMY, 2010).

Estudos no campo da Psicologia Social, por sua vez, no Brasil, que articulam especificamente o amor romântico à produção musical, ainda são incipientes, sendo boa parte da produção científica situada nas primeiras décadas do séc. XXI (BOLLOS, 2010; GARBUIO; FIORINI, 2015; HINKEL; MAHEIRIE, 2007; MENANDRO et al., 2003; NASCIMENTO; MARTINS, 2009; OLIVEN, 2011; SOUZA, 2013). Poucos são os estudos brasileiros, todavia, encontrados até o momento, que, tais como o presente estudo, utilizam as letras das canções como fonte de dados (COUTINHO et al., 2015).

\subsection{MÚSICA E REPRESENTAÇÕES SOCIAIS}

De acordo com Duarte (2002), a Teoria das Representações Sociais é um modelo conceitual adequado às demandas interpretativas de objetos musicais, tanto da perspectiva de sua criação quanto de sua apreciação. Isso porque, conforme explica a autora, a teoria integra em sua análise não só aspectos sociais e culturais, como também psicológicos e individuais, permitindo que o fenômeno musical seja enxergado em sua dupla posição, de produto e produtor de uma realidade social.

Alguns dos estudos que apresentam a vinculação entre a Teoria das Representações Sociais e a música incluem: investigações em representações sociais sobre a música como recurso no ensino de História (ABUD, 2005), representações sociais de crianças e práticas musicais (SUBTIL, 2005), representações sociais no contexto da pedagogia musical (DUARTE; MAZZOTTI, 2006), representações sociais da mulher no hip hop (MATSUNAGA, 2008), análise de representações sociais baseada em elementos gramaticais (SCARDUA; FILHO, 2010), representações da vida conjugal em músicas brasileiras da década de 1940 e 1960 (COUTINHO et al., 2015), representações de amor no rock brasileiro (NASCIMENTO et al., 2015) e representações sociais do fluxo musical (SECA, 2003). Todavia, conforme enfatizam Coutinho et al. (2015), não obstante o aumento do número de produções envolvendo a relação entre música e aspectos psicossociais desde o final da década de 1990, poucas são as pesquisas que utilizam a letra das canções como fonte de dados ou referência principal. 
O presente estudo visa a contribuir no preenchimento de ambas as lacunas, através da investigação das representações sociais de amor contidas nas letras das músicas mais reproduzidas nas rádios do Brasil no ano de 2015. Acreditamos, como Menandro e Nascimento (2007), que através da música popular - especialmente nos dias atuais, em que as paradas de sucesso se renovam quase inteiramente de um ano para o outro - seja possível resgatar os reflexos de representações sociais em evidência na contemporaneidade, contidos nas letras das canções estudadas.

\subsection{TEORIA DAS REPRESENTAÇÕES SOCIAIS}

A Teoria das Representações Sociais derivou da tese de doutorado do psicólogo social Serge Moscovici, publicada em 1961, intitulada “A psicanálise, sua imagem e seu público" (MOSCOVICI, 1961). O estudo visava a entender como se dá o processo de reapropriação e ressignificação de conhecimentos reificados da comunidade científica por grupos leigos em uma determinada sociedade. Mais especificamente, de acordo com Vala (2004), a pesquisa identificava como aspectos teóricos e práticos da Psicanálise, teoria então em evidência na França, eram reapropriados e vivenciados pela população de modo geral, em seu dia-a-dia. Umaña (2002) ressalta que, apesar de a Psicanálise ser o princípio organizador da obra, seu conteúdo se dirigia a um objetivo mais abrangente - o entendimento da natureza do pensamento social.

Vala (2004) postula que, de acordo com a Teoria, dois são os processos sociocognitivos responsáveis pela formação das representações sociais, os quais são intrinsicamente interdependentes: a objetivação e a ancoragem. Conforme explica Jodelet (2002), na objetivação há a transformação de uma ideia ou conceito em esquemas ou imagens concretas, ao passo que na ancoragem tais imagens são vinculadas a estruturas mentais já presentes na memória do indivíduo.

Duarte (2002), aplicando o conceito de objetivação aos objetos musicais, cita exemplos de composições europeias do período romântico naturalizadas no cotidiano dos sujeitos contemporâneos, como a Abertura da Nona Sinfonia de Beethoven, atualmente vinculada às celebrações matrimoniais, e os quatro primeiros acordes da Quinta Sinfonia, do mesmo autor, contemporaneamente objetivadas em 'música de suspense'.

Em relação ao segundo processo da gênese das representações sociais - a ancoragem -, o que se tem é o processo pelo qual o indivíduo visa a representar novas informações em uma estrutura que lhe seja mais familiar (MOSCOVICI, 2003). Conforme detalha Jodelet (2002), a ancoragem atua de duas maneiras durante a formação das representações: por um lado, enraíza seu objeto em uma rede de significações que possibilita seu funcionamento coerente face aos valores sociais apresentados e, através da memória, situa o novo conhecimento em noções prévias, já consolidadas. O efeito desse movimento é a redução das tensões entre os conhecimentos já solidificados do indivíduo e as novas informações que lhe estão sendo apresentadas (UMAÑA, 2002). Nesse sentido, a ancoragem funciona como uma forma de classificação e denominação (SÁ, 1993), semelhante ao processo de construção de categorias identitárias (VALA, 1997). Para Vala (2004), apesar de ambos os processos, isto é, a categorização e a ancoragem, funcionarem como estabilizadores do meio e redutores de novas aprendizagens, o processo de ancoragem é mais complexo, pois leva à produção de transformações nas representações já estabelecidas.

O processo de ancoragem é, assim, por um lado anterior à objetivação e, por outro, posterior a ela (CABECINHAS, 2004). É anterior na medida em que qualquer tratamento da informação exige pontos de referência ou esquemas pré-estabelecidos nos quais se apoiar. E é posterior na medida em que se refere à função social das representações, isto é, permite que seja apreendido o modo pelo qual os princípios representados se organizam para exprimir e constituir as relações sociais (VIDRIO, 2003).

Conforme elabora Duarte (2002), no que diz respeito à relação da Teoria das Representações Sociais com a música, o processo de ancoragem pode ser observado tanto na criação quanto na recep- 
ção de objetos musicais. Isso porque tanto o criador quanto o apreciador referenciam o objeto musical através de categorias pré-estabelecidas, designando um nome, um sentido e um uso para o resultado dessa operação (DUARTE, 2002). Um objeto musical, portanto, não pode ser concebido separado de seu significado e de seu referente, uma vez que ao determinar um objeto musical e nomeá-lo, sua representação é integrada ao sistema sociocognitivo do indivíduo.

Tal constatação vai ao encontro do que postula Abric (1998, p. 27), quando escreve que "toda ocorrência musical é percebida, representada e reapropriada pelo indivíduo ou pelo grupo, e reconstruída em seu sistema cognitivo, integrada no seu sistema de valores de acordo com sua história e com os grupos que o cercam". É a partir da relação dialética entre a ancoragem e a objetivação que se articulam, portanto, os processos sociocognitivos das representações sociais de um determinado objeto musical, através das quais é possível observar como o social interfere na elaboração psicológica, e a psicológica, no social (VIDRIO, 2003). Conforme demonstrado nos estudos de Nascimento e colaboradores (2015), o amor romântico não só cumpre aos requisitos de constituição de um objeto de representações sociais como é, ainda, um dos temas centrais da música popular brasileira.

Sendo assim, apresenta-se como relevante a tarefa de conhecer as representações sociais de amor romântico contidas nas canções mais executadas nas rádios brasileiras em 2015. Acreditamos que tal entendimento poderá contribuir para o enriquecimento do debate e da reflexão sobre as representações compartilhadas por parte do povo brasileiro sobre o amor romântico.

\section{MÉTODO}

Foi realizado um estudo exploratório, de caráter documental, que teve como fonte de dados o conteúdo das letras das músicas mais tocadas nas rádios do Brasil no ano de 2015. O estudo documental (SÁ-SILVA, ALMEIDA, GUINDANI, 2009; PIMENTEL, 2001) a partir de canções populares tem se mostrado um valioso método para a exploração de temáticas correntes, uma vez que refletem e incidem sobre as representações de objetos sociais salientes no contexto de sua produção (MENANDRO; NASCIMENTO, 2007).

\subsection{FONTE DE DADOS E PROCEDIMENTO DE COLETA DOS DADOS}

Os dados foram coletados a partir do software de monitoramento de rádio AudioMonitor, que, atualmente, monitora e armazena informações referentes a músicas tocadas em 4.600 estações de rádio em todos os estados brasileiros, durante todos os dias da semana.

A partir do procedimento descrito, para a investigação das representações sociais de amor romântico presentes nas canções mais tocadas nas rádios do Brasil no ano de 2015, foram coletadas as letras das 100 músicas mais tocadas em todo o território nacional e selecionadas aquelas que retratavam a temática do amor romântico, tendo sido analisadas, portanto, 95 canções que atenderam a esse critério.

O intervalo de tempo considerado para coleta dos dados, efetuado a partir do software AudioMonitor, foi do primeiro dia de janeiro de 2015 ao dia 31 de dezembro de 2015. O estudo fez uso de uma tecnologia recentemente disponibilizada no Brasil - o monitoramento, registro e classificação em tempo real de canções executadas nas rádios brasileiras - e se apoiou em um corpus definido a partir do critério de número absoluto de execuções.

\subsection{TRATAMENTO DOS DADOS}

As canções contidas neste estudo foram organizadas em um arquivo de texto constituído pelas 95 canções selecionadas. Com o auxílio do software ALCESTE (Analyse Lexicale par Context d'un Ensemble de Segument de Texte), de Reinert (1990), para fins de análise do corpus de dados construído, 
utilizou-se a Classificação Hierárquica Descendente (CHD), que organiza as palavras, aqui tratadas como unidades contextuais, em um dendrograma (posicionamento das classes geradas pelo software em forma de árvore). Tal estrutura possibilita a visualização da análise estatística realizada, indicando a frequência das palavras representativas de cada classe, a força de ligação entre estas, os eixos e a saliência percentual de cada classe em meio ao total do corpus analisado. A partir da CHD, podem ser observados os vocábulos de maior $x^{2}$, isto é, de maior centralidade na narrativa, em colunas verticais descendentes, o que auxilia a tarefa interpretativa do pesquisador, tendo sido consideradas para apresentação e análise dos resultados as palavras com $x^{2} \geq 3,84$ (CAMARGO, 2005).

O processamento dos dados realizado por meio do software Alceste apresenta, ainda, as UCEs Unidades de Contexto Elementar, que são fragmentos do corpus que se correlacionam de forma mais representativa com cada uma das classes, fornecendo seu contexto discursivo. Às UCEs é atribuído um valor $x^{2}$, representativo da correlação identificada pelo software entre a UCE e a classe em que se encontra (REINERT, 1998).

\section{RESULTADOS}

Do corpus de 95 letras de música, isto é, das 95 Unidades de Contexto Inicial (UCI) que compuseram o banco de dados processado, $71 \%$ foi analisado pelo software Alceste; o equivalente, neste caso, a 226 Unidades de Contexto Elementar (UCEs) - estatisticamente, um bom índice de aproveitamento (KRONBERGER; WAGNER, 2002).

A análise lexical efetuada pelo software foi apresentada através da Classificação Hierárquica Descendente (CHD), formada por classes onde se observam os valores dos qui-quadrados de cada palavra relevante à composição de cada classe. A CHD dos termos pertencentes às letras das canções mais executadas nas rádios brasileiras foi sistematizada em 4 classes e organizadas em 2 eixos principais e 2 subcorpos referentes ao primeiro eixo, conforme Figura 1.

Figura 1. Dendrograma com as classes identificadas pelo software Alceste

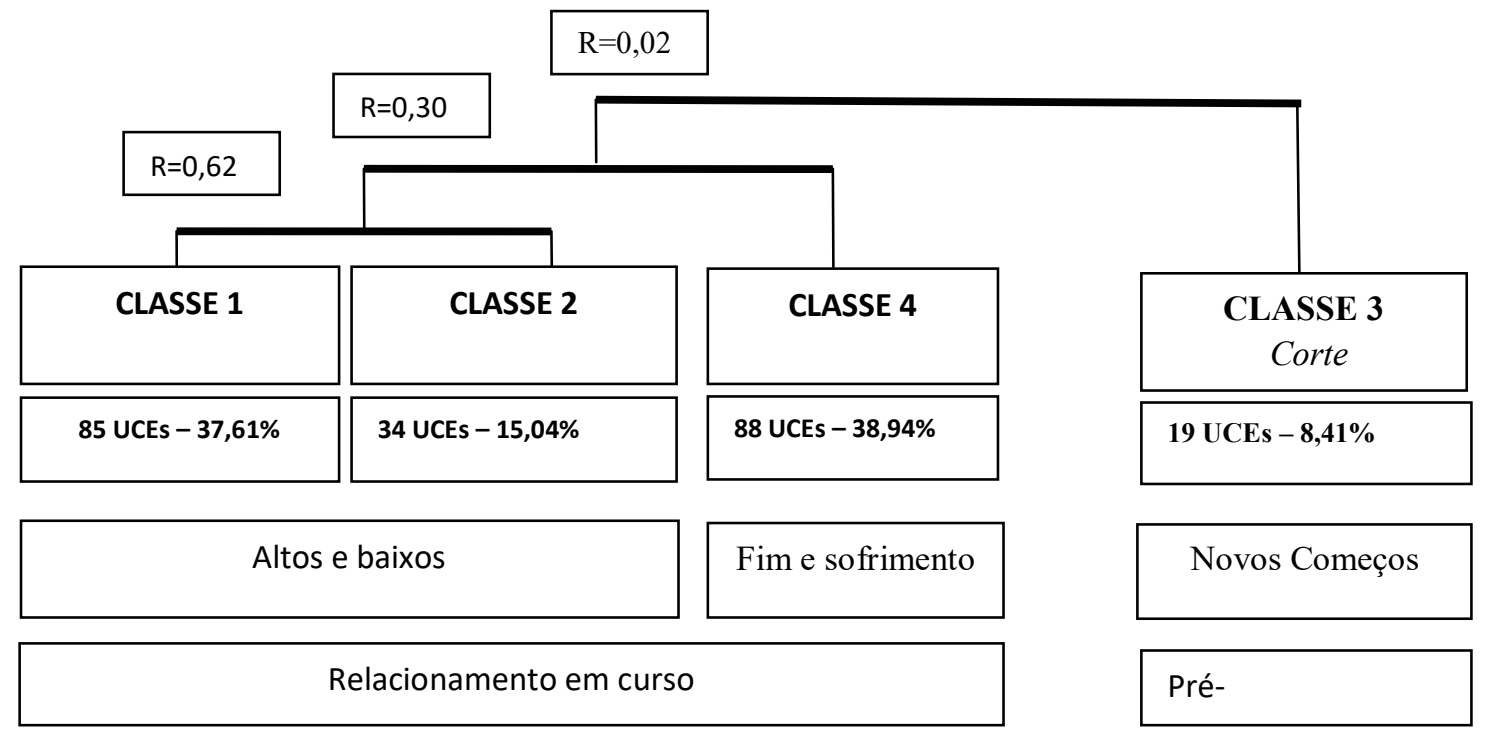

Fonte: Autores

As palavras foram organizadas em ordem decrescente em relação aos seus qui-quadrados, cujos valores representam a força de associação entre a palavra e a classe a qual pertence, e nomeadas, poste- 
riormente, em função de seus contextos (KRONBERGER; WAGNER, 2002). Para a contextualização dessas unidades lexicais, são apresentadas, ainda, as UCEs que compõem seu contexto narrativo na análise, conforme sugerido pelo software Alceste. Sua contextualização é reforçada a partir da apresentação do valor percentual da classe na totalidade do corpus analisado e com o R, que representa o grau de relação entre as classes.

No primeiro eixo (Figura 1), Relacionamento em curso, estão evidenciadas as classes relativas à interação entre dois indivíduos já na condição de casal. A narrativa deste eixo é íntima, e se dá entre duas pessoas que possuem uma história em comum. O eixo é formado por três classes distintas, nomeadas Lua de mel (Classe 1), Curso descendente (Classe 2) e Sozinho (Classe 4), com relação de $\mathrm{R}=30$ entre si. $\mathrm{O}$ subcorpo Altos e baixos retrata a variação entre os momentos de felicidade (Classe 1 - Lua de mel) e infelicidade (Classe 2 - Curso descendente) de um casal, e apresenta uma correlação de $\mathrm{R}=0,62$, o que indica forte conexão entre seus conteúdos (MENANDRO, 2004). O segundo eixo Relacionamento em curso se contrapõe ao eixo Pré-relacionamento, composto pela Classe 3 , que descreve situações anteriores ao início do relacionamento formal entre os sujeitos que se cortejam.

$\mathrm{Na}$ Classe 1, foram reunidas 86 palavras e 85 UCEs (37,61\% do corpus analisado), com uma média de 17,94 palavras analisadas por UCE. Já a Classe 2 apresenta 70 palavras e 34 UCEs (15,04\%

Tabela 1. Classificação Hierárquica Descendente da Classe 1 - Lua de mel

\begin{tabular}{|l|l|l|l|}
\hline Termo & Chi-2 & Termo & Chi-2 \\
\hline Ver & 18.03 & Desejo & 6.75 \\
\hline Te & 15.96 & Seu & 6.26 \\
\hline Dizer & 14.72 & Amor & 5.96 \\
\hline Amar & 13.45 & Mais & 5.88 \\
\hline Mundo & 10.26 & Ainda & 5.88 \\
\hline Caminho & 10.22 & Quero & 5.84 \\
\hline Vez & 9.63 & Manha & 5.49 \\
\hline Amo & 9.63 & Vi & 5.04 \\
\hline Só & 9.54 & Louco & 5.04 \\
\hline Tempo & 9.08 & Corpo & 5.04 \\
\hline Sonho & 8.80 & Passou & 4.94 \\
\hline Faz & 8.39 & Mesmo & 4.94 \\
\hline Você & 7.93 & Mal & 4.94 \\
\hline Viver & 7.27 & Acordarei & 4.94 \\
\hline Pensar & 7.12 & Tão & 4.69 \\
\hline Lembro & 6.75 & Vejo & 3.92 \\
\hline Estar & 6.75 & Veio & 3.92 \\
\hline Voz & 6.75 & Nesse & 3.92 \\
\hline Raridade & 6.75 & Mentira & 3.92 \\
\hline Mil & 6.75 & & \\
\hline
\end{tabular}

Fonte: Autores 
do corpus), com uma média de 19,29 palavras analisadas por UCE. O subcorpo a que as Classes 1 e 2 se conectam, Fim e sofrimento, é formado por uma única classe (Classe 4 - Sozinho), composta por 88 UCEs (38,94\% do corpus) e 58 palavras, com média de 17,84 palavras por UCE. Neste eixo, são evidenciados tanto comportamentos de tentativa de retorno quanto de conformidade com o fim do relacionamento.

Por fim, o segundo eixo, Novos começos, corresponde, cronologicamente, à primeira etapa no drama da corte, isto é, à abordagem que um sujeito dirige ao outro, que poderá ou não dar origem ao relacionamento romântico. O eixo conta apenas com a Classe 3, Corte, que responde por 19 UCEs $(8,41 \%$ do total) e 94 palavras, com uma média de 17,13 palavras por UCE. As palavras que compõe cada uma das classes, bem como seus contextos e eixos de relação são descritos e contextualizados a seguir.

A Classe 1 (Tabela 1), Lua de mel, se refere ao ideal romântico do ponto de vista do apaixonado, com promessas de amor eterno, incondicional e monogâmico. Nesta fase, observa-se um discurso feliz e otimista, vinculado ao momento inicial do cortejo. Esse conteúdo corresponde à fase da lua de mel, dentro das fases apontadas por Horton (1957) e Pontual e colaboradores (2016).

A palavra 'ver', por exemplo, que aparece com o maior chi-quadrado da classe (Tabela 1), surge no corpus em contextos de declaração de amor, tanto no sentido literal ("tudo é nada sem você, eu tô chegando pra te ver") quanto no sentido figurado ("raridade é ver que o mundo hoje é meu e seu, é confiar em mim"). A segunda palavra mais representativa dessa classe, 'te', revela tanto o caráter íntimo e dialogado das letras das músicas quanto seu conteúdo predominantemente interativo: “já te amo tanto sem te conhecer", "quando te vi, a paixão veio à tona”. O termo 'dizer', por sua vez,

Tabela 2. Classificação Hierárquica Descendente da Classe 2 - Curso descendente

\begin{tabular}{|l|l|l|l|}
\hline Termo & Chi-2 & Termo & Chi-2 \\
\hline Embora & 39.99 & Falar & 12.12 \\
\hline Diz & 30.10 & Coração & 11.62 \\
\hline Favor & 28.87 & Está & 11.45 \\
\hline Chama & 28.87 & Agora & 10.69 \\
\hline Sentir & 23.33 & Hora & 10.02 \\
\hline Ou & 23.33 & Diga & 6.34 \\
\hline Ir & 23.33 & Bater & 6.34 \\
\hline Tentar & 18.58 & Fora & 5.89 \\
\hline Deixou & 17.97 & Duvida & 5.89 \\
\hline Também & 16.88 & Vai & 5.44 \\
\hline Sente & 16.88 & Entender & 4.11 \\
\hline Chorar & 16.46 & Precisar & 3.89 \\
\hline Por & 14.71 & Tantos & 3.89 \\
\hline Sair & 12.85 & Seja & 3.89 \\
\hline Porta & 12.85 & Pois & 3.89 \\
\hline Falar & 12.85 & Entrar & 3.89 \\
\hline Termo & Chi-2 & Termo & Chi-2 \\
\hline & & & \\
\hline
\end{tabular}

Fonte: Autores 
aparece tanto vinculado ao termo anterior (te) (“Quero te dizer sem medo de amar, eu quero você”) quanto em outros contextos de declaração romântica ("Eu te amo e devia dizer todo dia, meu mundo tem um jeito todo seu" e "Teu jeito simples de dizer que sou especial").

A palavra 'amar', frequente em todo o corpus deste estudo, se destaca na Classe 1 em contextos otimistas , como nos trechos: "Só o amor faz voar, meu amor, vivo pra te amar" e "Enquanto a luz do sol brilhar, não vou parar, eu vou te amar". A próxima palavra da CHD, 'mundo', se ajunta ao rol de figuras de linguagem hiperbólicas utilizadas em declarações de amor romântico, conforme pode ser observado em "O teu sorriso, meu mundo, ficar sem, não sou capaz" e "Quero ser seu mundo, vem com tudo, vem matar o meu desejo".

Ainda na Classe 1, 'Caminho', termo com o chi-quadrado de 10.22, é utilizado nesta classe em seu sentido figurado ("Os nossos caminhos diferentes me levam a você"), bem como literal ("No caminho compro flores, nossa noite de amor as flores vão testemunhar”). A próxima palavra, 'vez', é utilizada para dar ênfase à recorrência do sentimento amoroso, conforme pode ser observado em "Essa mistura louca de desejo, me perco toda vez que eu te vejo" e em "Toda vez que você liga, o meu coração dispara e tudo faz sentido".

O software destaca, ainda, determinados trechos das canções analisadas, aqui chamadas de UCEs. Um exemplo de UCE apresentada pelo Alceste é extraído da canção Suíte 14, da dupla sertaneja Henrique e Diego: "E o que me faz ver o dia mais lindo, viver em paz, nós dois num só caminho. Vou de mansinho, veja, te amo, odeio, mas mesmo assim quero você" $\left(x^{2}=17\right)$.

A Classe 2 (Tabela 2), Curso descendente, refere-se tanto a incertezas e crises no relacionamento quanto a indícios de que ele está muito próximo do fim, contrariando as expectativas do que fora planejado na Classe 1. O tom do discurso é mais sombrio, e o descompasso entre o planejado e a realidade do momento é frequentemente atribuído ao comportamento do outro, uma vez que a música, predominantemente escrita em tom de diálogo, apresenta a versão dos acontecimentos do ponto de vista do cantor.

O fim do relacionamento, todavia, é aqui apenas uma projeção, que aparece, de acordo com a canção, de forma mais ou menos decidida. A primeira palavra da Tabela 2, 'embora', já anuncia o tom do discurso proferido nesta classe. Em trechos como "Estou indo embora, a mala já esta lá fora, vou te deixar. Por favor, não implora, porque homem não chora" ou "Diz você, diz o que vai ser da gente agora, ou me ama ou deixa eu ir embora", podem ser observados elementos da terceira fase do curso descendente, isto é, a ameaça de abandono. A palavra 'diz' manifesta a incredulidade do cantor frente às promessas de sua parceira: "diz que morre de amor por mim agora, depois de ter chorado rios, depois de tanto ter sofrido" ou "Você mente quando diz que está em outra e não quer mais voltar".

A próxima palavra, 'favor', aparece no contexto da súplica (por favor), que se utiliza da palavra anterior, 'diz', para expressar seu desejo: “diz, fala tudo, por favor. Que mal te fiz eu? Pra me tratar assim como farrapo. Diga, que mal te fiz eu?" e "Diz que aceita, por favor, vale a pena lutar pra salvar o nosso amor". Tal momento dialoga com aquilo que é descrito pela segunda cena do curso descendente, chamado de forças hostis (Horton, 1957), que representam momentos de tensão em um relacionamento, onde uma das partes percebe a presença de elementos desestabilizantes. O próximo termo, 'chama', aparece no corpus com dois significados distintos: (1) o verbo chamar, aqui representando a quarta cena do curso descendente (separação final): "Não me chame mais de amor, não me importo se você chorar. Eu não ligo, eu acho pouco pra quem nunca soube amar"; e (2) o substantivo chama, aqui relacionado à cena 1 (separação temporária): "Eu vou rezar pra gente se entender, eu tenho um plano pra reacender a nossa chama".

O termo 'sentir', verbo emblemático de um corpus predominantemente romântico, faz coro aos itens anteriores ao se referir à ameaça de abandono do curso descendente ("segue esse seu caminho, tenta me deixar sozinho. Vai sentir na pele a falta de um grande amor" e "Você vai sentir 
a falta de mim, você vai chorar, mas eu não vou ligar"). A palavra 'ou' também está presente em ultimatos sentimentais: "cê que sabe amor, se a gente fica junto ou dá um tempo" e "diz você, diz o que vai ser da gente agora, ou me ama ou deixa eu ir embora". 'Ir', ainda vinculada à saída de um dos indivíduos de uma relação, se apresenta na maior parte dos casos como descritiva da deserção do outro ("se que ir, então vai. Vai pra casa do carai. Se não me ama, então vai"), surgindo associada também ao primeiro termo da CHD ('embora'): "fala só pra não me dar moral que tá quase fazendo as malas, que vai pra Curitiba, vai tentar a vida, e não ir embora seria errar de novo".

As UCEs características da Classe 2 se relacionam com o momento da despedida e com as emoções a ele relacionadas. Na UCE constituída a partir da canção Porque Homem Não Chora, do cantor Pablo, podem ser observadas ameaças de abandono emitidas, de forma dialogada, pelo cantor: "porque homem não chora, Pablo, estou indo embora, a mala já esta lá fora, vou te deixar. Por favor, não implora, porque homem não chora e não pede perdão" $\left(\mathrm{x}^{2}=54\right)$ (Porque Homem Não Chora, Pablo).

A Classe 4, Sozinho (Ver Tabela 3), trata dos possíveis cursos de ação escolhidos pelo sujeito que se depara com a própria solidão após o fim do relacionamento. Conforme pode ser observado na Tabela 3, o conteúdo desta classe possui, em grande parte, características trágicas, e frequentemente é associado ao arrependimento, ao ressentimento e ao consumo de bebida alcoólica.

Tabela 3. Classificação Hierárquica Descendente da Classe 4 - Sozinho

\begin{tabular}{|l|l|l|l|}
\hline Termo & Chi-2 & Termo & Chi-2 \\
\hline Lua & 44.94 & Continuar & 6.63 \\
\hline Voltar & 42.11 & Tenho & 6.34 \\
\hline Rua & 34.03 & Nos & 6.16 \\
\hline Beber & 34.03 & Noite & 5.34 \\
\hline Viola & 33.12 & Sorriso & 4.97 \\
\hline Esperar & 33.12 & Sonho & 4.97 \\
\hline Casa & 27.06 & Peito & 4.97 \\
\hline Ninguém & 13.56 & Onde & 4.97 \\
\hline Morrer & 13.40 & Inventar & 4.97 \\
\hline Ate & 11.74 & Conter & 4.97 \\
\hline Dois & 11.13 & Assim & 4.85 \\
\hline Poder & 9.15 & Mulher & 4.53 \\
\hline Fácil & 6.63 & Ter & 3.85 \\
\hline Dessa & 6.63 & & \\
\hline
\end{tabular}

Fonte: Autores

A fase corresponde à etapa do Fim e sofrimento, dentro da classificação de Pontual e colaboradores (2016), que se subdivide em momentos de súplicas por uma nova chance e de aceitação do fim da relação. O fim do ciclo amoroso é lamentado, principalmente, através do abuso de bebida alcoólica, muitas vezes, descrito de forma orgulhosa pelo indivíduo etilista.

A primeira palavra, 'lua', aparece tanto como lamento ("E o que me prometeu, será que se esqueceu? De todos nossos planos, nossos filhos, nosso apartamento, da nossa lua de mel, do nosso casamento? 
Como pude acreditar nesse seu juramento? E agora estou sozinho outra vez"; "Que burrice você fez, destruiu os nossos planos em troca de uma noite no motel. Esqueceu da nossa linda lua de mel") quanto como composição do cenário infeliz ("Arrancou de mim a paz, o sorriso e a razão. É no som da viola que o peito chora, nessas noites de lua jogado na rua. Ai, amor, nessas noites de lua jogado na rua").

O termo 'voltar', que aparece em segundo lugar, está presente tanto no discurso daquele que aceita que o relacionamento acabou ("quem sabe eu ache alguém para me fazer feliz, que queira tudo aquilo que você não quis, que saiba dar valor ao meu amor e que me queira bem. Não tem mais volta, foi ponto final, quebrou o cristal") quanto no discurso daquele que não está certo disso ("Deus, a dor que ela deixou em mim, por favor me ajude a suportar. Deus, me tire o frio da solidão e essa sensação que ela não vai voltar"), bem como, ainda, no discurso do homem que não aceita o fim ("Vai ser difícil eu me apaixonar de novo, e a culpa é sua. Antes embriagado do que iludido, acreditar no amor já não faz mais sentido. Eu vou continuar nessa vida bandida até você voltar"). 'Rua' é o local que se opõe ao conforto íntimo do relacionamento ("Cansei de ficar sozinho, na rua não tem carinho, me leva pra casa. No amor sempre fui bandido, e agora que estou perdido me leva pra casa; "Não vou negar que vou sentir saudade sua, quem sabe um dia a gente continua. Posso pirar, me declarar pelos bares da rua e esculpir o seu rosto na lua").

Tabela 3. Classificação Hierárquica Descendente da Classe 4 - Sozinho

\begin{tabular}{|l|l|l|l|}
\hline Termo & Chi-2 & Termo & Chi-2 \\
\hline Ela & 27.57 & Olha & 5.55 \\
\hline Sabe & 20.52 & Quis & 5.11 \\
\hline Gostoso/a & 14.70 & Procurar & 5.11 \\
\hline Amiga & 11.47 & Gostar & 5.11 \\
\hline Pegar & 9.67 & Alguém & 4.97 \\
\hline Dela & 9.67 & Mas & 4.77 \\
\hline Baladas & 9.67 & Pelo & 4.77 \\
\hline Sofrer & 8.23 & Pega & 4.77 \\
\hline Gordinha & 8.02 & Mandar & 4.77 \\
\hline Dançar & 8.02 & Faca & 4.77 \\
\hline Quem & 7.99 & Culpa & 4.77 \\
\hline Aquele & 6.93 & Cansei & 4.77 \\
\hline Tá & 6.66 & Bebendo & 4.77 \\
\hline Sozinha & 6.39 & Tô & 4.57 \\
\hline Solteiro & 6.39 & Vontade & 4.54 \\
\hline Será & 6.39 & Outro & 4.54 \\
\hline Fica & 6.39 & Melhor & 4.54 \\
\hline Ex & 6.39 & Boca & 4.54 \\
\hline Apaixonar & 6.39 & Minha & 4.16 \\
\hline Hoje & 6.32 & Deu & 4.16 \\
\hline Tava & 5.95 & Mulher & 4.10 \\
\hline & & & \\
\hline
\end{tabular}


O verbo ‘beber' é emblemático desta classe, sendo o consumo alcoólico o método mais recorrentemente citado como reação à dor amorosa: "Quantas noites e quantas garrafas preciso beber pra tirar do meu peito essa mágoa, pra te esquecer?"; "Mas se a gente não voltar, posso beber, posso chorar, e até ficar no choro". 'Rua', 'lua' e 'beber' se misturam no trecho "Sem noites de lua, sem rumo na rua, em busca de um bar pra tentar te esquecer. Eu chego atrasado, tá tudo fechado, não tenho ninguém, nem lugar pra beber".

Uma das canções que compõe o corpus que apresenta de maneira exemplar esse comportamento chama-se Meia-noite e Meia, da dupla sertaneja Guilherme e Santiago, conforme UCE: "Meia noite e meia, Guilherme e Santiago, sem noites de lua, sem rumo na rua, em busca de um bar pra tentar te esquecer. Eu chego atrasado, tá tudo fechado, não tenho ninguém, nem lugar pra beber" $\left(\mathrm{x}^{2}=20\right)$ (Meia-noite e Meia, Guilherme e Santiago).

A Classe 3, Corte (Ver Tabela 4), retrata as diferentes estratégias adotadas pelo indivíduo no momento da conquista. Como pode ser observado na Tabela 4, seu conteúdo é diversificado e varia em função da abordagem utilizada pelo personagem da canção para atingir seus objetivos de sedução.

O momento do relacionamento romântico retratado nessa classe é o da corte, conforme a classificação de Horton (1957). Apesar de representar uma atividade específica, observa-se nela grande pluralidade de circunstâncias em que se encontram os emissores do discurso. Diversas canções, por exemplo, descrevem a realidade do solteiro que busca conquistar a pessoa amada através de métodos particulares, muitas vezes, descritos em detalhes. A corte, todavia, não é retratada unicamente a partir dessa perspectiva. Conforme será descrito nos parágrafos seguintes, esta fase retrata, frequentemente, o ponto de vista da pessoa que, interessada em outra, tanto sofre a partir de sua indecisão quanto se regozija com qualquer progresso realizado na conquista.

A primeira palavra da CHD, 'ela', simboliza a predominância do ponto de vista masculino no interior de tais narrativas ("Eu abro a porta e puxo a cadeira do jantar à luz de velas pra ela se apaixonar. Eu mando flores, chocolates e cartão"; "Para conquistar uma mulher, tem que ter carinho, tem que ter jeitinho, tem que dar aquilo que ela quer"). "Sabe", o próximo termo, vem em diversas instâncias associado ao termo anterior (ela), ressaltando que, ainda que o foco do discurso seja a mulher amada, o ponto de vista adotado é o do homem, que a enquadra em um estereótipo de dominatrix ("ela é maluca, é linda e sabe que é gostosa, que me olha, me encara, é super poderosa"; "ela quer me dominar. Joga a bomba e corre, ela foge porque sabe que dá choque ao simples toque"). A próxima palavra, 'gostoso/a', se refere tanto ao corpo masculino ("Sei que sou gostoso, pode conferir meu bem. Eu já peguei sua amiga, mas quero você também. Tem pra todo mundo, não precisa preocupar") quanto ao feminino ("Que ignorância da sua mãe, que te fez tão gostosa assim. Que covardia do seu pai, deixar você sair"; "Ê mundinho que dá tanta volta, cheguei na ex-gordinha, tá ainda mais gostosa"), porém ambas as posições de enunciação são masculinas. Uma terceira utilização da palavra presente no corpus é, ainda, em relação ao sexo propriamente dito ("Pensa num trem doido que é gostoso. Hoje não tem choro nem migué, se essa sapequinha cair na minha lagoa, hoje eu sou jacaré"; "te dei um abraço e falei baixinho no seu ouvidinho, vamos lá pra casa que eu faço gostosinho").

As UCEs destacadas pelo Alceste retratam os diversos momentos da corte. Observam-se, nas canções Ex-Gordinha, de Fred e Gustavo, Instigante, do grupo Sorriso Maroto e Imagina Com as Amigas, de Bruninho e Davi, uma maior ênfase nos traços físicos e de personalidade da mulher a quem dirigem a canção: "olha a gordinha na balada, cheia de má intenção. Ela quer eu, rá, de novo eu. Tá viciada na minha boca e eu querendo afastar" $\left(\mathrm{x}^{2}=43\right)$ (Ex-Gordinha, Fred e Gustavo).

\section{DISCUSSÃO}

Conforme evidenciado pelos resultados, o tema privilegiado das canções mais executadas nas rádios do Brasil em 2015 é o amor romântico (BOLLOS, 2010; GARBUIO; FIORINI, 2015; HINKEL; 
MAHEIRIE, 2007; MENANDRO et al., 2003; NASCIMENTO; MARTINS, 2009; OLIVEN, 2011; SOUZA, 2013), com letras que estabelecem, de maneira consistente, o papel social atribuído a cada um dos sujeitos na dinâmica do relacionamento amoroso. Na maior parte dos casos, tais papeis se encontram associados a procedimentos específicos de conquista, mantenimento, encerramento e recomeço do ciclo romântico.

Os principais resultados encontrados demonstraram, portanto, conteúdo predominante do ideal romântico de relacionamento afetivo, repleto de referências que nos ajudam a compreender as dinâmicas estabelecidas entre os seus integrantes e o ambiente em que se encontram inseridos, cujas narrativas das músicas contêm descrições bem definidas do que seria o amor romântico (MARTINS-SILVA; TRINDADE; JUNIOR, 2013): um amor intenso, eufórico, sofrido, capitaneado pela figura masculina e associado, frequentemente, à bebida alcoólica.

Nessa dinâmica do ciclo romântico, o desenrolar do drama da corte, de Horton (1957), em muito se assemelha às representações sociais das relações amorosas retratadas nas músicas na atualidade, que seguem as seguintes etapas: homem e mulher se conhecem (corte), oficializam o relacionamento (lua de mel), se desentendem (curso descendente) e rompem o relacionamento (fim). Apesar de o mesmo roteiro poder ser observado nas canções analisadas por este estudo, uma mudança no pano de fundo merece reflexão crítica: a pervasividade do contato íntimo sexual. O ciclo romântico se desenvolve, frequentemente, entre indivíduos que, conforme indicam as letras das canções, já se relacionaram, ou se relacionam, desde o período da corte, sexualmente, e que já possuem um histórico sexual com outros parceiros. Vale ressaltar, ainda, que o amor cantado nos dados identificados neste estudo se refere a uma realidade heteronormativa, sendo ausente qualquer menção à diversidade sexual e de gênero.

Ao descrever, de forma estável e consistente, os elementos característicos do universo representacional do relacionamento romântico (NASCIMENTO et al., 2015), as narrativas apresentadas no corpus deste estudo estabelecem os limites do que é legítimo em cada etapa constitutiva em tal relacionamento, e indicam quais são as interações possíveis e aceitáveis dentro de cada uma delas. Isso ocorre, segundo estabelece a Teoria das Representações Sociais (JODELET, 2002; MOSCOVICI, 2003; VALA, 2004), em função das convicções compartilhadas por membros dos diversos grupos sociais a respeito de um objeto. Em se tratando de letras de canções, tais representações sociais, através de seus processos constitutivos de objetivação e ancoragem, qualificam o conteúdo musical e preenchem seus predicados, os quais, por sua vez, são selecionados em função delas, em um movimento dialético (DUARTE, 2002).

A manutenção, assim, de representações antigas em uma realidade que pouco condiz com aquela em que tais imagens foram construídas exemplifica a resistência das representações sociais a mudanças em seus elementos centrais, os quais são responsáveis por sua estabilidade e permanência (MOSCOVICI, 2003). Percebe-se, todavia, a ausência de repertórios culturalmente sancionados referentes à forma de lidar com tais representações conflitantes, de forma que os sujeitos são levados a distorcer determinados atributos específicos do objeto representado a fim de reduzir as dissonâncias entre o real e o ideal para o objeto cuja representação social está sendo trabalhada (WAGNER et al., 1995). Essa distorção, todavia, nem sempre é capaz de justificar todas as dissonâncias emergentes em tais contextos (JODELET, 2002), o que pode resultar em ciúmes, violência e desespero, como pode ser observado nas letras de determinadas canções do corpus analisado.

A pluralidade de situações vinculadas ao amor romântico evidencia a realidade das representações sociais, que se espelham em práticas sociais vigorantes dentro do contexto histórico-social ao qual se referem e se tornam, elas mesmas, parte do acervo de representações que mantêm tais práticas (JODELET, 2002). Dois aspectos de tais representações, contudo, foram observados de maneira mais recorrente: as dinâmicas entre o feminino e o masculino, e a associação do amor romântico à bebida alcoólica.

Como pode ser percebido, a imagem do homem que seduz diversas mulheres é apresentada de forma naturalizada e até admirada. Ademais, uma vez que a protagonização de quase todas as canções 
é masculina, tende-se a atribuir à figura do homem o papel central na condução do relacionamento e nas decisões relativas aos rumos a serem tomados pelo casal. Observa-se, assim, com distinção, a etapa da descontextualização da objetivação (VIDRIO, 2003), isto é, o processo através do qual as características do que compõe um objeto são recortadas e apresentadas, de maneira reiterada e através de informações dispersas, em um núcleo figurativo cujos elementos constitutivos serão considerados suficientes para a objetificação de um objeto.

As representações sociais apresentadas em tais obras não rompem, todavia, com a objetivação do relacionamento romântico a partir de critérios polarizadores de masculino e feminino, mas apenas os invertem. Tem-se, assim, um conteúdo ancorado nas próprias representações masculinas de relacionamento, em suas mesmas dinâmicas, ao invés de um modelo original ou um questionamento, ainda que parcial, na dinâmica a partir da qual derivam seus conteúdos. Ou seja, o que se encontra nas letras das canções parece se ancorar em representações sociais voltadas para a centralidade do universo masculino, com pouco ou nenhum espaço para o contraponto feminino. A esse respeito, afirmam os autores Coutinho et al. (2015): "O que se encontra nas letras é o discurso do homem falando sobre si, sobre a mulher, sobre o casamento, predominando o discurso masculino nas letras" (p. 469).

No que se refere à bebida alcoólica, esta aparece associada tanto à felicidade e à celebração quanto à tristeza e ao desolamento, em ambos os casos vinculada ao relacionamento romântico. Quando apresentada em contextos de celebração, são adicionados elementos relacionados à felicidade, ao bem-estar, à amizade e ao sucesso. Também nesse caso, os efeitos negativos do comportamento apresentado são suprimidos ou minimizados (JODELET, 2002), dando lugar a representações que tratam essencialmente das características positivas do objeto, o que demanda reflexões quanto aos impactos sociais de tais representações (ABREU et al., 2010). Refletir sobre a música e suas representações sociais é, ao mesmo tempo, questioná-la e fazer com que esse questionamento dirija-se a uma realidade reconhecida, na esperança de que tal reflexão contribua para o enriquecimento das dinâmicas de negociação entre as diversas representações de conteúdos musicais intercambiados na constante interação entre os grupos sociais.

Finalmente, quanto às limitações do estudo, há que se apontar que, ainda que o rádio permaneça sendo um veículo de transmissão musical bastante difundido no Brasil, há diversas outras formas de consumo musical que não foram consideradas neste estudo, como o consumo a partir de mídias físicas (vinil, cassete, CD, DVD, Blu-ray) e digitais (arquivos de música e serviços de streaming). Tais formas de consumo musical apresentam, sobre o rádio, a vantagem de conferir ao ouvinte a possibilidade de escolha individual das faixas que serão escutadas. O estudo, ainda, se concentrou nas músicas mais tocadas nas rádios. Sabe-se, porém, que existe um campo fértil de canções relevantes para a análise que não se incluem dentre as que foram aqui analisadas, seja por emergirem de outras mídias, como os serviços de streaming, ou por surgirem de manifestações populares espontâneas, não comerciais, que não encontram espaço nas rádios. 


\section{Referências}

ABREU, et al. C. Uso de álcool em vítimas de acidentes de trânsito: estudo do nível de alcoolemia. Revista Latino-Americana de Enfermagem, v.18, n.1, p. 513-520, 2010.

ABRIC, J-C. A abordagem estrutural das representações sociais. In: MOREIRA, A.S.P.; OLIVEIRA, D.C. (Orgs.). Estudos Interdisciplinares de Representação Social. Goiânia: Editoda AB, 1998, p. 27-38.

ABUD, K. Registro e representação do cotidiano: a música popular na aula de história. Caderno Cedes, Campinas, v. 25 , n. 67 , p. 309-317, 2005.

ADAY, R. H.; AUSTIN, B.S. Images of aging in the lyrics of American country music. Educational Gerontology, v. 26, n.1, p. 135-154, 2000.

BARRAUD, H. Para compreender as músicas de hoje. São Paulo: Perspectiva, 1975.

BENNETT, A. Popular Music and Youth Culture: Music, Identity and Place. Canterbury: MacMillan, 2000.

BOLLOS, L. H. Canção do Amor Demais: marco da música popular brasileira contemporânea. Per musi, v.22, n.1, p. 83-89, 2010.

CABECINHAS, R. Representações sociais, relações intergrupais e cognição social. Paidéia, v.14, n.28, p. 125-137, 2004.

CAMARGO, B. V. ALCESTE: Um programa informático de análise quantitativa de dados textuais. In: A. S. P. MOREIRA; B. V. CAMARGO, J. C. JESUÍNO, S. M. Nóbrega (Orgs.). Perspectivas teórico-metodológicas em representações sociais. João Pessoa: Editora Universitária - UFPB, 2005, pp. 511-540.

COUTINHO, S. M. S., et al. Sonoridades da vida conjugal registradas em versos de cançoes brasileiras produzidas entre 1940 e 1960. Estudos de Psicologia (Campinas), v. 32, n. 3, p. 461-473, 2015.

DUARTE, M. Objetos musicais como objetos de representação social: produtos e processos da construção do significado de música. Em Pauta, v.13, n.20, p.123-140, 2002.

DUARTE, M.; MAZZOTTI, T. Representações sociais de música: aliadas ou limites do desenvolvimento das práticas pedagógicas em música? Educação \& Sociedade, v.27, n.97, p.1283-1295, 2006.

DUKES, R. L., et al. Expressions of love, sex, and hurt in popular songs: a content analysis of all-time greatest hits.

The Social Science Journal, v. 40, p. 643-650, 2003.

FRITH, S. Why do songs have words? In: S. FRITH (Ed.), Taking Popular Music Seriously: Selected Essays. United Kingdom: Routledge, 2007, p. 209-239.

GARBUIO, R. L.; FIORINI, C. F. “Amor" e "morte” nos madrigais de Carlo Gesualdo: um estudo sobre o desenvolvimento da escrita musical e textual. Per Musi, v.32, n.1, p.364-393, 2015.

GUÉGUEN, N.; JACOB, C.; LAMY, L. Love is in the air: Effects of songs with romantic lyrics on compliance with a courtship request. Psychology of Music, v.38, n.3, p.303-307, 2010.

HINKEL, J.; MAHEIRIE, K. Rap-rimas afetivas da periferia: reflexões na perspectiva sócio-histórica. Psicologia \& Sociedade, v.19, n.2, p. 90-99, 2007.

HORTON, D. The dialogue of courtship in popular songs. American Journal of Sociology, v.52, n.5, p.569-578, 1957. IBOPE. Dimension - 2018a. Disponível em: https:/www.kantaribopemedia.com/dimension-2018/

IBOPE. Book de Rádio - 2018b. Disponível em: https://www.kantaribopemedia.com/estudos-type/bookradio2018/

JACOB, C., et al. 'Love is in the air': Congruency between background music and goods in a flower shop. Internation- 
al Review of Retail, Distribution and Consumer Research, v.19, n.1, p. 75-79, 2009.

JODELET, D. As representações sociais: um domínio em expansão. In: D. Jodelet (Org.). As representações sociais. Rio de Janeiro: UERJ, 2002, p.17-44.

KRONBERGER, N.; WAGNER, W. Palavras-chave em contexto: análise estatística de textos. In: M. W. Bauer; G. Gaskell (Orgs.). Pesquisa Qualitativa com texto, imagem e som: um manual prático. Petrópolis: Vozes. 2002, p. 416-441.

MARKERT, J. (2001). Sing a song of drug use-abuse: four decades of drug lyrics in popular music - from the sixties through the nineties. Sociological Inquiry, v.71, n.2, p. 194-220, 2001.

MARTINS-SILVA, P. O.; TRINDADE, Z. A.; SILVA JUNIOR, A. Teorias sobre o amor no campo da Psicologia Social. Psicologia: Ciência e Profissão, v. 33, n. 1, p. 16-31, 2013.

MATSUNAGA, P. As representações sociais da mulher no movimento hip hop. Psicologia Social, v.20, n.1, p. 108-116, 2008 .

MENANDRO, P. R. M., et al. Aspectos do relacionamento amoroso presentes em letras de músicas dirigidas à camada popular urbana. Arquivos Brasileiros de Psicologia, v.54, n.1, p. 03-19, 2003.

MENANDRO, P. R. M.; NASCIMENTO, A. R. A. Análise de Conteúdo de material documental pré-existente à investigação: o caso da música popular. In: M. M. B. RODRIGUES; P. R. M. MENANDRO (Orgs.). Lógicas metodológicas: trajetos de pesquisa em psicologia. Vitória: UFES. 2007, p.214-221.

MIRANDA, M. L. De J.; GODELI, M. R. C. S. Música, atividade física e bem-estar psicológico em idosos. Revista Brasileira de Ciência e Movimento, v.11, n.4, p.87-94, 2003.

MOSCOVICI, S. La psychanalyse, son image et son public. Paris: puf, 1961/1976.

MOSCOVICI, S. Representações sociais: investigações em psicologia social. 4. ed. (Trad. P. A. Guareschi). Petrópolis: Vozes, 2003

NASCIMENTO, A. R. A.; MARTINS, A. S. A saudade amorosa na canção brasileira: um estudo exploratório (19271964). Psicologia Argumento, v.27, n.57, p. 161-173, 2009.

NASCIMENTO, A. R. A., et al. Representações sociais do amor no rock brasileiro dos anos 80. Psicologia \& Sociedade, v.27, n.1, p. 231-239, 2015.

NATTIEZ, J. Music and discourse. Princeton: Princeton University Press, 1990.

OLIVEN, R. G. The imaginary of Brazilian popular music. Virtual Brazilian Anthropology, v.8, n.1, p. 170-207, 2011.

PEATMAN, J. G. Radio and Popular Music. In: P. F. LAZARSFELD; F. N. STANTON (Eds.), Radio Research 194243. New York: Duell, Sloan \& Pearce, 1944, p. 335-393.

PIMENTEL, A. O método da análise documental: seu uso numa pesquisa historiográfica. Cad. Pesqui., n. 114, p. 179$195,2001$.

PONTUAL, M. A. D.; SILVA, O. R. M.; BONOMO, M. Representações de gênero nas músicas mais tocadas nas rádios brasileiras em 2014. In: 4 SEMINÁRIO INTERNACIONAL DE EDUCAÇÃO E SEXUALIDADE E 2 ENCONTRO INTERNACIONAL DE ESTUDOS DE GÊNERO, 2016, Vitória-ES. Anais... Caderno de Resumos do 4 Seminário Internacional de Educação e Sexualidade e 2 Encontro Internacional de Estudos de Gênero. Vitória-ES: UFES, 2016. Disponível em: http://www.gepsexualidades.com.br/resources/anais/6/1466392063_ARQUIVO_Trabalhocompletoparaevento.pdf

RAYNOR, H. História social da música: da idade média a Beethoven. Rio de Janeiro: Guanabara, 1986. 
REINERT, M. Alceste. Version 4.0 - Windows (Manual). Toulouse: Societé IMAGE. 1998.

REINERT, M. Alceste: une méthodologie d'analyse des données textuelles et une application: Aurélia, de Gérard de Nerval. Bulletin de Méthodologie Sociologique, v.26, n.1, p. 24-54, 1990.

SÁ, C. P. Representações sociais: o conceito e o estado atual da teoria. In: M. J. SPINK (Org.). O conhecimento no cotidiano: as representações na perspectiva da psicologia social. São Paulo: Brasiliense, 1993, pp.19-45.

SANTOS, M. J. D. Estereótipos, preconceitos, axé-music e pagode. 2006. 214f. Dissertação (Mestrado em Psicologia Social) - Programa de Pós-Graduação em Psicologia Social, Universidade Federal da Bahia, Bahia. 2006.

SÁ-SILVA, J. R.; ALMEIDA, C. D.; GUINDANI, J. F. Pesquisa documental: pistas teóricas e metodológicas. Revista Brasileira de História e Ciências Sociais, v.1, n.1, p.1-15, 2009.

SCARDUA, A.; FILHO, E. A. S. Analisando representações sociais através de elementos gramaticais: compondo representações sobre música. Psicologia \& Sociedade, v.22, n.2, p.374-381, 2010.

SCHEFF, T. J. What's Love Got to Do With It? United Kingdom: Routledge, 2011.

SECA, J-M. La "carte mentale" des musiques underground: approche exploratoire. In: M. LAVALEE, S.; VINCENT, C.; OUELLET.; C. GARNIER (Orgs.). Les Representations Sociales: Constructions Nouvelles. Montreal: UQAM, 2003, p.109-122.

SOUZA, C. R. Mário de Andrade: o sequestro do desejo e a música popular em versos. Revista do Instituto de Estudos Brasileiros, v.57, n.1, p. 111-138, 2013.

SUBTIL, M. J. D. Mídias, música e escola: práticas musicais e representações sociais de crianças de 9 a 11 anos. Revista da ABEM, Porto Alegre, v.13, n.1, p.65-73, 2005.

UMAÑA, S. A. Las representaciones sociales: ejes teóricos para su discusión. Cuaderno de Ciencias sociales, v.127, n.1, p.1-84, 2002.

VALA, J. Representações sociais e percepções intergrupais. Análise Social, v.32, n.140, p.7-29, 1997.

VALA, J. Representações sociais e psicologia social do conhecimento quotidiano. In: J. VALA; M. B. MONTEIRO (Orgs.). Psicologia Social. Lisboa: Fundação Calouste Gulbenkian, 2004, p.457-506.

VAN SICKEL, R. W. A world without citizenship: on (the absence of) politics and ideology in country music lyrics, 1960-2000. Popular Music and Society, v.28, n.3, p.313-331, 2005.

VIDRIO, S. G. Representaciones sociales, argumentación y lógica natural. Anuario de Investigación, v.1, n.1, p.620634, 2003.

VIRGÍLIO, P. Primeira transmissão de rádio no Brasil completa 90 anos. 2012. Disponível em: http://memoria.ebc. com.br/agenciabrasil/noticia/2012-09-07/primeira-transmissao-de-radio-no-brasil-completa-90-anos/

WAGNER, W., ELEJABARRIETA, F.; LAHNSTEINER, I. How the sperm dominates the ovum - objectification by metaphor in the Social Representation of conception. European Journal of Social Psychology, v.25, p.671-688, 1995. 


\begin{tabular}{cl} 
Histórico & Recebido em: 20/01/2017 \\
& Revisado em: 04/10/2018 \\
& Aceito em: 26/03/2019 \\
& Concepção: MADP; MB \\
& Coleta de dados: MADP \\
& Análise de dados: MADP; MB \\
& Elaboração do manuscrito: MADP; MB \\
& Revisões de conteúdo intelectual importante: MADP; MB \\
& Aprovação final do manuscrito: MADP; MB \\
& FAPES - Resolução 124/2014, bolsa para mestrado acadêmico. \\
\hline \multirow{2}{*}{ Financiamento } &
\end{tabular}

